\title{
Die rol van psigiatrie in die hantering van en navorsing oor gesinsmoord
}

\author{
J.L. Roos \\ Departement Psigiatrie \\ Universiteit van Pretoria \\ PRETORIA
}

\begin{abstract}
Very little research has been done on the phenomenon of family murders in the Republic of South Africa. In this anicle reference is made to the descriptive, qualitative and exploratory study of family murders, which was comied out by the HSRC. Psychiatric factors involved in family murders considered in the HSCR study are presented and the role of psychiatry at a primary, secondary and tentian level of prevention is discussed. In conclusion suggestions are made regarding the future role of psychiary in research relating to family murders.
\end{abstract}

\section{INLEIDING}

Min wetenskaplike navorsing oor gesinsmoord is al in Suid-Afrika gedoen. 'n Nasionale ondersoek deur die RGN (Olivier et al., 1991), wat oor 'n tydperk van twee jaar gestrek het, het egter meer lig op dié onderwerp gewerp. Die navorsing is beskrywend, omvattend en verkennend, en hoewel dit sekerlik nie antwoorde op al die vrae oor gesinsmoord bied nie, het dit sekere psigiatriese en psigologiese faktore geïdentifiseer wat moontlik tot dié verskynsel bydra. Daar is ook ander faktore buite die psigiatrie wat 'n rol speel, maar dit word nie hier bespreek nie.

Indien daar na die aard en omvang van 'n gesinsmoord gekyk word, is dit te verstane dat die media op 'n sensasionele manier daaroor verslag sal doen - 'n feit wat die afgelope tyd gelei het tot heelwat spekulasie oor die oorsake van gesinsmoord. Baie mites het voortgespruit uit hierdie wyse van verslag, en telkens word daar deur die dagblaaie gewys op die ernstige afmetings wat gesinsmoorde aanneem. Só ernstig was die omvang van gesinsmoord dat die regering navorsing oor dié probleem aangevra het (Olivier $e t$ al., 1991). Daar is egter geen betroubare statistiek beskikbaar oor gesinsmoorde in Suid-Afrika nie, aangesien die Suid-Afrikaanse Strafreg gesinsmoord nie as 'n afsonderlike verskynsel klassifiseer nie, maar wel as moord gevolg deur selfmoord. Syfers gerapporteer deur Graser (1987:262) in koerantverslae toon 'n toename van $87 \%$ in die voorkoms van gesinsmoord van 1983 tot 1985 (tien gevalle is in 1983 gerapporteer, en sewentien gevalle in 1985). 
Redes wat deur koerantberiggewing as oorsake vir gesinsmoord aangegee word sluit onder andere die volgende in:

- "Apartheid major factor in regard to family murders" (The Star, 1987-08-19).

- "Sexual problems trigger family murders" (The Sunday Star, 1988-01-17).

- "Family killing 'acts of mercy"' (Weekend Post, 1988-01-09).

- "Epidemic of family killings due to Afrikaner character trait" (Sundcry Tribune, 1985-05-12).

- "Father power gets blame for family murders" (Weekend Argus, 1988-09-17).

- "Vaders moor gesinne uit wanhoop" (Beeld, 1984-11-10).

- "Men who pump bullets into their children have mercy in their hearts - expert" (The Sunday Star, 1987-09-27).

Een koerant noem selfs hondsdolheid as moontlike oorsaak van gesinsmoord (Die Burger, 1984-03-13). Soos Graser (1991:50) tereg opmerk, is die sinvolste van hierdie opskrifte waarskynlik "Gesinsmoorde bly onverklaarbaar" (Beeld, 1983-07-23). Dit word weer beklemtoon dat, hoewel die RGN-studie (Olivier et al., 1991) 'n verkennende studie is wat nader beweeg aan antwoorde op tergende vrae oor gesinsmoord, gesinsmoord nie altyd verklaarbaar is nie.

Daar is soveel verskillende soorte familie-uitwissings dat dit moeilik is (indien nie onmoontlik nie) om 'n enkele, eenvoudige definisie daarvoor te gee. Die definisie van gesinsmoord is 'n gekompliseerde saak waarin daar verskeie faktore oorweeg moet word soos motiewe, presipiterende faktore en die modus operandi (Graser, 1991:52).

'n Mens moet besef dat daar 'n verskil is tussen moord binne die gesin, en moord gevolg deur selfmoord (wat nie noodwendig binne die raamwerk van gesinsmoord val nie). 'n Breër definisie van gesinsmoord is nodig wanneer motiewe, presipiterende faktore en die modus operandi in ag geneem word, en 'n aantal nader omskrewe definisies van gesinsmoord soos byvoorbeeld 'altruistiese' gesinsmoord in ag geneem word (De Jongh van Arkel, 1985:141).

Die RGN-studie (Olivier et al, 1991) het 'n gesin gedefinieer as individue wat, volgens kontrak of ooreenkoms, intiem saamleef en as 'n eenheid funksioneer in 'n sosiale en emosionele stelsel. Gesinsmoord is dus die doelbewuste uitwissing van die bestaande gesinstelsel deur ' $n$ lid van die gesin, of die voorneme om dié stelsel uit te wis, met sekere in- en uitsluitingskriteria. Hierdie kriteria neem juis hierdie ander gevalle van moord binne 'n gesin en gesinsgeweld in ag. 


\section{DIE ROL VAN PSIGIATRIE IN DIE HANIERING VAN GESINSMOORD}

Psigiatrie is 'n vertakking van die geneeskunde wat handel met geestesversteurings. Die manifestasies van hierdie siektes is hoofsaaklik op 'n gedrags- of psigologiese vlak (Kaplan \& Sadock, 1988:1).

In 'n loodsstudie oor die rol van psigiatrie en 'n daaropvolgende nasionale ondersoek is 17 gevalle van gesinsmoord ondersoek (Roos et al, 1991).

Dié ondersoek kan beskou word as 'n beskrywende, kwalitatiewe, verkennende studie. Navorsingsinstrumente het ingesluit ongestruktureerde en in-diepte-onderhoude, persoonlike dokumente en deelnemende waarneming. Vir 'n meer omvattende uiteensetting oor die navorsingsmetode, word verwys na die artikel van Schurink in hierdie uitgawe.

Die volgende psigiatriese diagnoses is by die 17 gesinsmoordenaars gemaak:

Kliniese psigiatriese sindroom

- Gemoedsversteurings (depressiewe versteurings) $14(83 \%)$

- Major depressie

- Aanpassingsversteuring met depressie 2(12\%)

- Major depressie met psigose $1(6 \%)$

- Bipolêre versteuring - depressie $1(6 \%)$

* Delusionele versteuring $1(6 \%)$

- Gemengde substansverbruikversteuring $1(6 \%)$

- Persoonlikheidsversteuring $1(6 \%)$

Antisosiale tipe $\quad 1(6 \%)$

Omskrywing van persoonlikheidstrekke:

- Afhanklik $9(53 \%)$

- Obsessief $3(18 \%)$

- Paranoies $3(18 \%)$

- Impulsief $2(12 \%)$

- Antisosiaal $1(6 \%)$

- Neuroties $1(6 \%)$

- Histrionies $1(6 \%)$

- Skisotipies $1(6 \%)$

Die selfmoordpatroon van die 14 gesinsmoordenaars met gemoedsversteuring nadat 
die moord gepleeg is, was soos volg:

$\begin{array}{ll}\text { Selfmoord } & 7(50 \%) \\ \text { Selfmoordpoging } & 4(29 \%) \\ \text { Selfmoordideasie, maar geen poging } & 2(14 \%) \\ \text { Geen ideasie } & 1(7 \%)\end{array}$

By die voorafgaande 14 gesinsmoordenaars het nege (64\%) voorheen selfmoord-ideasie of selfmoordpogings aangewend, en twee (14\%) het vorige dreigemente van gesinsmoord gehad.

Dit is nie slegs die psigopatologie teenwoordig in die gesinsmoordenaar wat gesinsmoord veroorsak nie. Die gesinsmoordenaar is in interaksie met ' $n$ familie en/of 'n huweliksverhouding. Binne hierdie interaksie en verhouding kan stressore geaktiveer word deur sekere gebeure. Hierdie gebeurtenisse hang ook af van die ondersteuningsbronne en aanpassingsmeganismes van die individuele familielede, en van die familie as 'n sisteem.

By die hantering van 'n pasiënt wat met gesinsmoord dreig, moet die psigiater besef dat dit nie 'n 'eenmanvertoning' is nie. 'n Multiprofessionele spanbenadering is hier noodsaaklik. Die lede van so 'n multiprofessionele span sluit in 'n psigiater, 'n kinderpsigiater, 'n huisarts, 'n distriksgeneesheer, 'n kliniese sielkundige, 'n psigiatriese of ander maatskaplike werker, 'n psigiatriese verpleegkundige, 'n pastor en arbeidsterapeute. Noue skakeling met welsynsorganisasies, kerke, skole en ander menslike diensgroepe is van wesentlike belang.

Indien psigiaters wil bydra tot die doeltreffende hantering van gesinsmoord sal al die mense en organisasies wat hiervoor beskikbaar is, ingespan moet word. Groot dele van die land het nie toegang tot gekwalifiseerde, professionele dienste nie. Daar moet dus gekyk word na hulpbronne en mense wat op 'n diepgaande grondslag beskikbaar is. Hierdie hulpbronne sluit kerk- en gemeenskapsorganisasies op plaaslike vlak in. Die kerk is moontlik die mees onderskatte en onderbenutte geestesgesondheid-hulpbron in Suid-Afrika.

\section{$2.1 \quad$ Voorkomende psigiatriese behandeling}

Voorkoming in psigiatrie verwys na drie vlakke van intervensie (Caplan, 1964), naamlik:

- Primêre voorkoming verwys na die bevordering van 'n aktiewe staat van posi- 
tiewe gesondheid (wat die bevordering van optimale lewens- omstandighede insluit), reeds voor die ontwikkelingsstadium van probleme of simptoomontwikkeling.

- Sekondêre voorkoming betrek intervensie en kan die vroeë en doeltreffende herkenning of diagnose en 'behandeling' insluit. Dié behandeling kan 'n wye spektrum insluit wat wissel van algemene ondersteuning, omgewingsmanipulasie tot'n vlak van professionele intervensie.

- Tersiêre voorkoming verwys na die beperking van inkorting (limitation) en rehabilitasie.

Die vraag kan dus gestel word wat die psigiater kan aanbied by die hantering van die gesinsmoordvraagstuk wanneer daar na die drie vlakke van voorkoming in psigiatrie gekyk word.

\subsubsection{Primêre voorkoming}

Die klem is hier op ' $n$ aktiewe toestand van positiewe geestesgesondheid wat 'n klimaat van optimale lewensomstandighede insluit. Primêre voorkoming impliseer reeds ingryping voor die ontwikkelingstadium van 'n siekte-sindroom. Hoewel die psigiatrie ingryp op 'n primêre voorkomingsvlak (byvoorbeeld by serebrale sifilis), is daar nog 'n groot agterstand in Suid-Afrika op dié gebied. 'n Goeie voorbeeld van primêre voorkoming in die geneeskunde in ons land is egter die programme ter voorkoming van VIGS wat bekendgestel is.

Die primêre voorkoming van gesinsmoord het baie fasette. Dit sluit algemene strategieë in soos om mense lewensvaardighede aan te leer om stres beter te hanteer. Dit vereis ook die aktiewe betrokkenheid van die gemeenskap, waar mense mekaar help en meer omgee vir ander. Die opleiding van primêre geestesgesondheidsorg-personeel maak ook deel uit van hierdie basiese voorkomingsaspek. Hierdie primêre voorkomingstrategieč moet gerig wees op alle mense in die samelewing - ook dié wat op afgeleē plekke bly. Die sosiale konteks (Olivier et al., 1991:294) waarbinne gesinsmoord plaasvind (wat die mikrostelsel van die familie, én die makrostelsel per se in Suid-Afrika insluit), moet ook in ag geneem word.

Opleiding in die volgende basiese lewensvaardighede behoort aangebied te word:

* probleem- en konflikoplossing,

- selfgelding, 
- 'n 'omgee'-houding teenoor ander mense en teenoor die lewe in die algemeen,

* 'n doeltreffende kommunikasiestyl,

- streshanteringsprogramme by die skool, werkplek en tuis,

- vryetydsbesteding,

* huweliksvernykingsprogramme wat fokus op:

- die oorgang van 'n patriargale huwelikstelsel na 'n vennootskap-tipe huwelik,

- konstruktiewe verskille in die huwelik sonder dat die selfbeeld van enige van die lede geskaad word,

- die vermoë om die huwelik te laat ontwikkel in 'n onafhankliker stelsel wat gegrond is op wedersydse respek en volwasse verantwoordelikheid, seksuele kommunikasie en 'n seksuele verhouding wat vervulling vir albei partye daarstel.

- huweliksoriëntasie vir mense wat beplan om te trou, met die klem op:

- die voorbereiding vir 'n vennootskap-tipe huwelik,

- seksualiteit,

- die noodsaak om 'n individuele persoonlikheid en belangstelling binne die huwelik te behou,

- die inruim en benutting van kwaliteit-tyd saam,

- die belang van betrokkenheid by gemeenskapsaktiwiteite en sinvolle vryetydshantering

* ouerskap, wat insluit:

- die effek van die geboorte van 'n baba op die huwelikstelsel,

- die omskrywing van kinders se behoeftes,

- die omskrywing van natuurlike ontwikkelingsfases van kinders en die veranderende rol wat ouers tydens elke fase speel,

- die beklemtoning van die noodsaaklikheid dat 'n kind 'n onafhanklike mens moet word,

- hulp aan die ouer in die kind se voorligting oor seksualiteit,

- finansiële bestuur en street law. Laasgenoemde aspek verwys na programme wat die publiek oplei oor algemene wetsaspekte, hul regte en hul voorregte.

Dié opleidingsprogramme moet op 'n basiese gesondheidsorgvlak aangebied word, en die media moet ook in die aanbieding van sulke programme ingespan word. 


\subsection{Sekondêre voorkoming}

Hier gaan dit oor daadwerklike optrede en kan vroegtydige en doeltreffende diagnose en behandeling ingesluit word.

'n Hoë persentasie gesinsmoordenaars ly aan gemoedsversteurings (depressie) en trekke van persoonlikheidsversteurings (Olivier et al., 1991; Roos \& Olivier, 1991; Roos \& Bodemer, 1989:122). Hierdie psigiatriese faktore in 'n persoon met sekere psigososiale stressore en interaksies binne die betrokke familie is die moontlike dryfveer agter die uiteindelike gesinsmoord.

In die gesinsmoordondersoek deur die RGN (Olivier et al., 1991) het $83 \%$ van die gesinsmoordenaars aan 'n gemoedsversteuring (depressie) gely. Bo alle verwagting het major depressie met psigose by slegs $6 \%$ voorgekom, terwyl $59 \%$ aan major depressie gely het. Meer as die helfte van gesinsmoordenaars $(53 \%)$ het afhanklike persoonlikheidstrekke gehad. Psigososiale stressore met 'n hoë insidensie het huweliks- en finansiële probleme ingesluit. Hierdie bevindings vind tot 'n sekere mate aansluiting by Rosenbaum en Bennet (1986:368) se bevindings.

Rosenbaum en Bennet (1986:368) het bevind dat die volgende faktore ' $n$ rol speel by depressiewe pasiënte met 'n risiko vir mansiag en moord, gevolg deur selfmoord:

- 'n persoonlikheidsversteuring of trekke van 'n persoonlikheidsversteuring,

- as kind mishandel,

- 'n geskiedenis van alkohol- en substansmisbruik,

vorige selfmoordgedrag,

- depressie, gepresipiteer deur seksuele ontrouheid van 'n huweliksmaat (werklik of verbeeld).

Dit is bekend dat selfmoord die algemeenste aggressiewe daad is wat depressiewe pasiënte pleeg. Dit is uiters belangrik dat die geneesheer of lid van die multiprofessionele span wat depressiewe pasiënte behandel, nie net sal uitvra oor selfmoordgedagtes nie, maar ook sal uitvra oor gedagtes en intensies wat verband hou met manslag, gerig op naby-familie (veral waar daar beskikbare slagoffers soos jong kinders is).

Dit moet in gedagte gehou word dat die behandeling van depressiewe pasiënte met gedagtes van manslag teenoor hulle families veel meer insluit as net die voorskryf van antidepressiewe middels. Moontlike strategieë om hierdie pasiënte te hanteer sluit in sentra vir krisisintervensie, wetgewing wat verseker dat sulke mense spoedig uit die samelewing verwyder kan word, en 'n multi-dissiplinêre benadering tot die betrokke familie. 
Tydens 'n gesinsmoordondersoek deur die RGN (Olivier et al., 1991) het dit duidelik geblyk dat die huidige Geestesgesondheidwet (Wet no. 18 van 1973) nie altyd prakties uitvoerbaar is waar ' $n$ persoon dreig met gesinsmoord en nie bereid is om in 'n psigiatriese hospitaal opgeneem te word nie. Waar so 'n persoon as 'n "spoed-eisende geval" (Artikel 12 van die Wet op Geestesgesondheid) in 'n psigiatriese hospitaal opgeneem moet word, is daar dikwels na-ure en oor naweke nie 'n geneesheer of 'n landdros beskikbaar nie - veral 'n probleem op afgeleë plekke. Die Suid-Afrikaanse Polisie is ook huiwerig om in te meng indien die nodige wetlike dokumentasie nie beskikbaar is nie.

Dit is noodsaaklik dat 'n persoon wat dreig met gesinsmoord gehospitaliseer moet word - of in 'n private psigiatriese hospitaal, of in 'n staatspsigiatriese hospitaal. Die psigiater wat besluit om 'n persoon wat dreig met gesinsmoord nie te hospitaliseer nie, moet seker wees dat dié persoon nie sy dreigement sal uitvoer indien hy nie gehospitaliseer word nie. Dit bly egter altyd 'n probleemsituasie, en dikwels voel private psigiaters dat, hoewel hulle die persoon wat met gesinsmoord dreig kan hanteer, hulle nie altyd oor ' $n$ multiprofessionele span beskik om die ander gesinslede en familie te hanteer nie. Gevolglik word hierdie pasiënte wat met gesinsmoord dreig meestal na staatspsigiatriese hospitale verwys - vrywillig of as spoedeisende opnames. Langtermyn-psigoterapie met die oog op persoonlikheidsgroei en verandering is dikwels nodig nadat die aanvanklike krisis onder beheer is. Daar moet egter in gedagte gehou word dat die persoon wat met gesinsmoord dreig nie die enigste fokuspunt vir behandeling is nie. Dikwels is ander vorms van psigoterapie ook nodig, soos huweliksterapie, familieterapie en individuele psigoterapie vir die eggenoot/eggenote van die persoon wat met gesinsmoord dreig.

Die besluit oor die ontslag van 'n pasiënt wat met gesinsmoord dreig na 'n periode van hospitalisasie, is dikwels ' $n$ krisispunt in die hantering van hierdie pasiënte. Die besluit om ' $n$ pasiënt te ontslaan, berus by die multiprofessionele span. Daar moet egter verseker word dat die pasiënt nie meer 'n gevaar inhou om die gesinsmoorddreigemente uit te voer nie. Hoewel dit gewoonlik ' $n$ moeilike besluit is, is al die lede van die multiprofessionele span betrokke by die pasiënt en het hulle insig in die individuele en familieprobleme. By ontslag moet seker gemaak word van individuele opvolgdienste en ondersteuningsbronne vir die pasiënt en sy familie.

\subsubsection{Tersiêre voorkoming}

Dit is onmoontlik om alle gevalle van gesinsmoord te voorkom. Wat is dus die rol van die psigiater nadat 'n gesinsmoord plaasgevind het? Eerstens is dit om die hof behulpsaam te wees in die evaluering van gesinsmoordenaars wat die daad oorleef het, en 
tweedens die rehabilitasie van oorlewende gesinslede, familie en ander instansies betrokke by die gesinsmoord.

Die hof sal slegs by uitsondering iemand wat 'n gesinsmoord gepleeg het nie vir 'n observasietydperk na 'n psigiatriese hospitaal stuur nie (volgens die bepalings van Artikels 77 en 78 van die Strafproseswet). Die aard van die misdaad, wat indruis teen sosiale norme, is dikwels die dryfveer agter hierdie verwysings deur die hof.

'n Artikel 77- of 78-verwysing volgens die Strafproseswet verwag van psigiaters om hulle uit te spreek oor die volgende aspekte:

* of daar 'n psigiatriese diagnose by die beskuldigde gemaak kan word,

* die verhoorbaarheid van die beskuldigde,

- die toerekeningsvatbaarheid ten tye van die pleeg van die misdaad.

Gewoonlik word drie psigiaters aangestel om 'n psigiatriese verslag volgens die Strafproseswet op te stel: 'n staatspsigiater, 'n hofpsigiater en 'n psigiater vir die verdediging. Die psigiater vir die verdediging is opsioneel en dit hang van die beskuldigde se regsverteenwoordiger af of so 'n psigiater aangestel sal word.

Die beskuldigde word vir minstens dertig dae opgeneem in ' $n$ staatspsigiatriese hospitaal soos deur die hof bepaal. Hierdie periode van observasie kan verleng word na gelang van die oordeel van die betrokke psigiaters. Tydens die observasieperiode word psigiatriese onderhoude met die beskuldigde gevoer. Spesiale ondersoeke na sy fisiese welstand word gedoen - hierdie ondersoeke sluit onder andere in bloedondersoeke, 'n elektroënkefalografiese ondersoek, X-strale, rekenaartomografiese ondersoeke en ander ondersoeke (indien nodig). Die beskuldigde word psigometries geëvalueer, en

- 'n maatskaplike agtergrondverslag word ingewin. Tersaaklike hofverrigtinge en feite rondom die gebeure word ook aan die psigiaters beskikbaar gestel. Die psigiater moet deurentyd besef dat nie alle gesinsmoordenaars noodwendig geestesversteurd is nie.

Indien die hof bevind dat die beskuldigde ten tye van die misdaad geestesversteurd was, word die beskuldigde terugverwys na 'n psigiatriese hospitaal en word hy as 'n Presidentspasiënt beskou. 'n Staatspsigiater is dan betrokke by die behandeling en rehabilitasie van so 'n pasiënt totdat ontslagprosedures in werking gestel word. Hierdie rehabilitasie en behandeling mag jare duur. Dit is belangrik dat die psigiatriese hospitaal nie as 'n plaasvervanger vir 'n gevangenis moet dien nie. Indien die pasiënt (gesinsmoordenaar) se psigiatriese toestand behandel en gerehabiliteer is, moet ontslagprosedures in werking gestel word, ongeag die duur van behandeling in die psigiatriese hospitaal. 
Die rehabilitasie van oorlewende gesinslede, familie en ander instansies betrokke by die gesinsmoord, is 'n aspek van behandeling wat dikwels verwaarloos word en waaroor daar min in die literatuur berig word. Die hantering sluit aan by die hantering van familie en vriende na 'n persoon selfmoord gepleeg het. Schneidman (1971:455) wys daarop dat dié mense gehelp moet word met hulle foltering, skuldgevoelens, angs, verleentheid en verwarring. Hy beklemtoon dat selfmoord nie 'n geïsoleerde, persoonlike tragedie is nie. Dit is ook 'n interpersoonlike gebeurtenis wat rampspoedige afmetings aanneem. Dit is dus te verstane dat sommige oorblywendes aan 'n posttraumatiese stresversteuring kan ly - ' $n$ toestand wat met behulp van psigoterapeutiese maatreëls en medikasie hanteer moet word.

Hoewel daar sekere gemeenskaplike trekke in gesinsmoord is, is dit noodsaaklik dat die psigiater bedag moet wees op die nuanses van 'n spesifieke gesinsmoord, en om dienooreenkomstig die toepaslike hanteringstrategieë te kies. Gesinsmoord word nooit maklik deur enigiemand verstaan of aanvaar nie, maar die impak daarvan sal oor die algemeen groter wees op onvolwasse mense. Dit moet veral in gedagte gehou word by die hantering van oorblywende kinders.

Uit 'n RGN-ondersoek (Olivier et al., 1991:313) het dit geblyk dat die gesin se swart werkers, asook onervare polisiebeamptes, dikwels hulp nodig het na so 'n gebeurtenis. Die psigiater moet altyd by 'n spesifieke gesinsmoord hierdie mense in gedagte hou en ook aan hulle hulp verleen.

\subsection{Die rol van die psigiater by navorsing oor gesinsmoord}

Soos reeds genoem, is daar nog min wetenskaplike navorsing oor gesinsmoord in SuidAfrika gedoen. Die psigiater word hoofsaaklik gekonfronteer met gesinsmoord wanneer hy pasiënte moet evalueer wat dreig met gesinsmoord, wanneer hy pasiënte wat gesinsmoord gepleeg het vir hofdoeleindes moet evalueer, of wanneer hy oorlewendes moet behandel.

Hoewel die resultate van die betrokke RGN-studie op sekere psigiatriese faktore dui wat betrokke mag wees by gesinsmoord, kan daar geen definitiewe gevolgtrekkings oor die oorsake van hierdie verskynsel gemaak word nie. Meer diepgaande ondersoeke moet nog oor gesinsmoorde gedoen word.

Moontlike inligtingsbronne vir die ontsluiting van die verskynsel van gesinsmoord kan die volgende wees:

gesinsmoordenaars wat vir observasie vir hofdoeleindes onder die Strafproses- 
wet 1977 verwys word,

- pasiënte wat dreig met gesinsmoord,

- mense wat gesinsmoord pleeg en daarna selfmoord pleeg.

Daar moet egter in gedagte gehou word dat gesinsmoord, soos kindermishandeling, geklassifiseer moet word as ' $n$ sindroom in eie reg, en dat dit regstatus in die Suid-Afrikaanse Strafreg behoort te kry. Indien dit gebeur, sal verseker word dat die regs- en natuurwetenskap professionele aandag daaraan sal skenk. Dit sal gevolglik moontlik wees om statistieke by te hou oor dié verskynsel sodat die presiese omvang daarvan geëvalueer kan word.

Dit moet ook in gedagte gehou word dat, hoewel die rol van die psigiater in navorsing oor gesinsmoord beklemtoon word, dit vanuit verskeie perspektiewe deur 'n multiprofessionele span nagevors moet word. So 'n navorsingsprojek moet psigiatriese, sielkundige, kriminologiese, sosiologiese, teologiese, maatskaplike en regsperspektiewe insluit.

\subsection{Bronne van gesinsmoord vir wetenskaplike ondersoeke}

2.3.1 Gesinsmoordenaars wat vir observasie vir hofdoeleindes onder die Strafproseswet, 1977 verwys word

Hoewel daar nie 'n groot aantal van hierdie pasiënte na psigiatriese hospitale verwys word nie, is dit ' $n$ waardevolle bron van ondersoek en wel om die volgende redes:

Die gesinsmoordenaar lewe nog en eerstehandse inligting kan van hom/haar verkry word.

- In hierdie geval is baie volledige psigiatriese ondersoeke beskikbaar en daar is altyd twee en soms meer psigiaters by die ondersoek betrokke. Hierdie psigiaters kom onafhanklik tot hulle gevolgtrekkings wat bevindings akkurater maak.

- Retrospektiewe probleme soos ondervind by die psigologiese outopsiemetode van Litman et al. (1984:924), word uitgeskakel.

- Bykomende inligtingsbronne is beskikbaar soos inligting van die hof, psigometriese toetsing, maatskaplike agtergrondinligting en observasie deur verpleegkundiges.

Die verskillende groot psigiatriese hospitale kan hulle data saamvoeg om te verseker dat 'n groter aantal gesinsmoordgevalle ondersoek word. 
Daar moet in gedagte gehou word dat hierdie gesinsmoordenaars 'n geselekteerde groep kan wees omdat hulle nie selfmoord na die gesinsmoord gepleeg het nie, en omdat sommige psigiaters vooropgestelde idees mag hè dat gesinsmoordenaars altyd geestesversteurd moet wees.

\subsubsection{Pasiēnte wat dreig met gesinsmoord}

Al hoe meer pasiënte wat met gesinsmoord dreig, word gestuur vir psigiatriese evaluasie. Sodanige pasiënte is weer eens 'n eerstehandse bron van inligting oor moontlike veroorsakende faktore in gesinsmoord. Die vraag is egter of die groep mense wat met gesinsmoord dreig, oor dieselfde kam geskeer kan word as diegene wat gesinsmoord volvoer. Die navorser weet nie of 'n persoon wat met gesinsmoord dreig, wel tot die daad sou oorgegaan het indien intervensie nie plaasgevind het nie.

Dit is bekend in psigiatrie dat die mense wat selfmoorddreigemente uiter en diegene wat inderdaad selfmoord pleeg, twee verskillende groepe uitmaak. Daar mag egter 'n mate van oorvleueling tussen dié twee groepe wees, en dit laat 'n mens wonder of dit nie ook die geval by gesinsmoord is nie.

Ondanks bogenoemde argumente, kan daar baie geleer word van mense wat dreig met gesinsmoord oor moontlike veroorsakende faktore, en daar kan geleer word hoe om die hanteringsprosedures van hierdie pasiënte te vertyn.

\subsubsection{Persone wat gesinsmoord pleeg en daama selfmoord pleeg}

Wanneer daar aan die hof gerapporteer word dat 'n sterfgeval nie as gevolg van natuurlike oorsake was nie, gee die landdros opdrag aan die distriksgeneesheer of enige ander mediese praktisyn om die oorsake van die dood te ondersoek. Indien daar na so ' $n$ ondersoek steeds twyfel oor die oorsaak van dood bestaan, kan die magistraat 'n post mortem of 'n geregtelike doodsondersoek gelas.

Die Wet op Geregtelike Doodsondersoeke (Wet no 58 van 1959) gee die landdros die mag om 'n post mortem te gelas om die oorsaak van dood met groter sekerheid vas te stel.

Die doel van 'n geregtelike doodsondersoek is om die omstandighede van dood meer volledig te ondersoek by 'n openbare verhoor. Die landdros moet die oorsaak en omstandighede van dood vasstel, en of enige persoon toevallig of krimineel vir die dood verantwoordelik gehou kan word. Die oorledene mag self verantwoordelik ge- 
hou word vir sy dood deur nalatigheid, onvoorsiene omstandighede of opsetlik (soos in die geval van selfmoord).

'n Landdros kan self 'n geregtelike doodsondersoek hou. Hy kan ook, met die toestemming van die Minister van Justisie, 'n assessor of twee assessore aanstel om saam met hom die ondersoek te hou. Assessore word aangestel vir hulle kennis van die reg (dikwels 'n afgetrede landdros), of vir hulle spesifieke kundigheid (soos in die geval van 'n patoloog). 'n Psigiater of 'n sielkundige mag ook aangestel word as 'n assessor in spesifieke selfmoordgevalle.

Indien iemand met spesifieke kundigheid oor gesinsmoord as assessor aangestel word, sou meer waardevolle inligting uit hierdie navorsingsbron verkry kan word as sonder so 'n persoon.

'n Mens vra jouself af of gesinsmoord in meer gevalle voorkom kan word. Alvorens meer wetenskaplike feite oor die oorsake van hierdie tragedies beskikbaar is, kan hierdie vraag nie beantwoord word nie. Die rol van 'n biologiese en genetiese predisposisie in aggressiewe gedrag van hierdie aard (moord gevolg deur selfmoord), behoort ook verder ondersoek te word. Hierdie aspekte is in aktiewe, aggressiewe selfmoord ondersoek (Asberg et al., 1976:1193). Dit is egter so dat psigiatrie 'n definitiewe rol te speel het in die hantering van en navorsing oor gesinsmoord. Meer navorsing is egter op dié gebied nodig om nader aan 'n antwoord te kom.

\section{BIBLIOGRAFIE}

ASBERG, M., TRASKMAN, L. \& THOREN, P. 1976. 5-HIAA in the Cerebrospinal Fluid: A Biochemical Suicide Predictor. Archives of General Psychiotry, 33:1193-1197.

BEELD 1983. Jul. 23.

- BEELD 1984. Okt. 11.

CAPLAN, G. 1964. Principles of Preventive Psychiatry. New York : Basic Books.

DIE BURGER 1984. Maart 13.

DE JONGH VAN ARKEL, J.T. 1985. Gesinsmoord: 'n pastorale-teologiese perspekticf. SuidAfrikaanse Tydskrif vir Strafneg en Kriminologie, 9(2):141-148.

GRASER, R.R. 1987. Family Murder; Some Considerations. South African Joumal of Law and Criminolog, 11:262-268.

GRASER, R.R. 1991. Family Murder in South Africa: Exploratory Notes. Acra Criminologica, 4(2): 5054.

KAPLAN, H.I. \& SADOCK, B.J 1988. Synopsis of Psychialry. Behavioural Sciences. Clinical Psychialry. Fifth Edition. Baltimore : Williams and Wilkins.

LITMAN, R., FARBEROW, N., SCHNEIDMAN, E., et al. 1984. Investigation of Equivocal Suicides. Joumal of the American Mectical Association, 924-929.

OLIVIER, L., HAASBROEK, C.P., BEYERS, D., DE JONGH VAN ARKEL, J.T., MARCHETTI, M.C., ROOS, J.L., SCHURINK, E.M., SCHURINK, W.J., VISSER, M.J. 1991. The Phenomenon of Family Murder in South Africa: An Exploratory Study. Pretoria : Human Sciences Research Council. 
Die rol van psigiatrie in die hantering van en navorsing oor gesinsmoord

ROOS, J.L. \& OLIVIER, L. 1991. Psigiatriese faktore betrokke by gesinsmoord in S.A.: 'n Verkennende studie. Ongepubliseerde referaat: Fakulteitsdag, Fakulteit Geneeskunde, Universiteit van Pretoria.

ROOS, J.L. \& BODEMER, W. 1989. Psigiatriese aspekte van gesinsmoord. Suid-Afrikaanse Mediese Joemaal, 75:121-123.

ROSENBAUM, M. \& BENNET, B. 1986. Homicide and Depression. American Joumal of Psychiatry, 143:367-370.

SCHNEIDMAN, E.S. 1971. Prevention, Intervention, and Postvention in Suicide. Annals of Internal Medicine, 75:453-458.

SUNDAY TRIBUNE 1985. Mei 12

THE STAR 1987. Aug. 19.

THE SUNDAY STAR 1987. Sept. 27.

THE SUNDAY STAR 1988. Jan. 17.

WEEKEND ARGUS 1988 . Sept. 17

WEEKEND POST 1988. Jan. 1.

Wette

Wet op Geestesgesondheid, No. 18 van 1973.

Wet op Geregtelike Doodsondersoeke, No. 58 van 1959.

Strafproseswet van 1977. 1992.09.22 